\title{
Music and Mediation
}

\section{Toward a New Sociology of Music}

\author{
chapter 22 part IV, in The Cultural Study of Music: A Critical Introduction, $2^{\text {nd }}$ edition \\ Martin Clayton, Richard Middleton, Trevor Herbert ed., 2012: 249-260
}

\author{
Antoine Hennion \\ MINES-ParisTech, CSI - Centre de sociologie de l'innovation, CNRS UMR 7185 \\ 60 bd St-Michel, 75006 Paris, France \\ antoine.hennion@mines-paristech.fr
}

After a century of studies, there is no agreement on what it means to construct a sociology of music. From the beginning this "of" has been a place of tension, not of smooth coordination. If music has easily attracted social readings, there has been strong resistance to a systematic sociology of music whose aim would be to explain musical values or contents through reference to sociological factors. The most vehement prosecutor of such alleged reductionism was undoubtedly Adorno (e.g., 1976) - even though he himself became the worst reductionist when it came to popular culture (Adorno 1990); for him, only musics that are not really art deserve sociological treatment (it is difficult to know if this is more disrespectful of popular music or sociology!). By contrast, the opposite program - a positive explanation of the ways in which music is produced, diffused, and listened to - has been attacked on the grounds that, given its refusal to address "music itself," it cannot acknowledge music's specificity.

In this opposition between two programs, a part of the question is specific to the case of music, but another is common to the social interpretation of any art. To a large extent, the sociology of art has defined itself through opposition to aesthetics. The aim was both to criticize any claim of autonomy for works of art and aesthetic judgment, and to return the experience of aesthetic pleasure - often regarded as immediate and subjective-to its social and historical determinations. The two types of causality mobilized above have often been described in social studies of art in terms of a distinction between studying either "the art object sociologically" or "the art object as a social process" (Zolberg 1990, chapters 3 and 4). One approach displays the mediators of art, the other how art mediates society. The latter takes art as an empirical given reality, and provides explanations of its social conditions; it can be respectful vis-à-vis the "artistic nature of art": the task of sociology is to give an account of the social conditions of its production, diffusion, and reception. The former shows art as a social artifact, or construction, of a group - an "art world"; as such, it is more invasive (it looks for the social nature of art, as Blacking (1973) would put it, not for wider social factors), and sees the claim of art to be autonomous as problematic.

These two directions, one clearly empiricist and more devoted to specific case studies, the other more theoretical, are themselves divided into different trends. Across the board, though, sociology has set itself against a purely internal and hagiographic aesthetic commentary on artworks, "filling out" an art world formerly only including a very few chefs-d'œuvre and geniuses. Mainstream productions and copies, conventions and material constraints, professions and academies, performance venues and markets, on the artistic side of the scene; and, on the social side, codes and rites of consumption, gender and ethnicity, and, in the specific case of music, modes of circulation in a "glocal" world: these are what have been pushed to the front of the scene. These mediations range from systems or devices of the most physical and local nature, to institutional arrangements and collective frames of appreciation 
such as the discourse of critics, right up to the very existence of an independent domain called art. In so doing, scholars have given up global, abstract systems of interpretation, and produced instead a practical theory of mediation, conceived as the reciprocal, local, heterogeneous relations between art and public through precise devices, places, institutions, objects, and human abilities, constructing identities, bodies, and subjectivities.

\section{A Sociology of Aesthetic Pleasure?}

Nevertheless, the relationship of sociology and art remained problematic. For most of the classical forms of sociology, for critical theory (Bourdieu 1984), and for interactionist (Becker 1982) or constructivist (DeNora 1995) currents, the sociological analysis of art has always been less interested in creation, genius, or the works "in themselves" than in what makes these categories appear as such. For Bourdieu, who took the critical intention furthest, it means unmasking the magical role of "creation." In this view, culture is a façade disguising social mechanisms of differentiation, artistic objects being "only" means to naturalize the social nature of tastes; aesthetic judgments are but denegations of this work of naturalization that can only be made if unknown as such. This critique of taste and of its social reproduction has led to many empirical surveys of musical consumption (e.g., DiMaggio 1987; Lamont and Fournier 1992; Peterson and Kern 1996). A radical lack of concern for the works themselves characterizes most of these studies. Sociology refuses subjectivism, the cult of genius, and the self-glorifying discourse of artists, preferring to demonstrate the constraints through which artists and amateurs are unknowingly determined, the conventions through which they recognize and create their world, and the formats used to mold the social construction of masterpieces.

In these conditions, any report on artistic experience in terms of beauty, sensation, emotion, or aesthetic feeling is automatically regarded as a manifestation of actors' illusions about their own beliefs (Bourdieu 1990), or the conventional products of a collective activity. The works do nothing, and the processes involved in their appreciation lose their specificity or specialness, as has deplored Frith (1996), pleading for an evaluation of popular cultures; works and tastes - meaningless in and of themselves - are returned to the arbitrariness (a key word in any analysis in terms of belief) of a collective election based on a social, non artistic principle. The argument is a powerful one, and should not be overlooked if we want to avoid the celebration of autonomous art simply being taken literally again. But one also has to measure the limits of such a view, particularly in view of the dominant position it long had in the sociology of art. It is becoming essential to reconsider sociology's lack of interest in works of art and the aesthetic experience as, echoing cultural studies (Hall and Jefferson 1976; Grossberg 1992; Frow 1995), did music sociologists DeNora (2000), Hennion ([1993] 2007, 2004) and A. Bennett (2000), moving from a constructivist to a more pragmatist position (Gell 1998): what do we do with art or music, and what does it produce, emotionally and collectively? Other way, there is a danger, that of reinforcing the great divide between expressive comments and analytical writings: between literary, subjective, "hot" accounts of musical experience on a side, as provided for example by cultural, gender or queer studies (but with a loosened constraint of rigour - the "what allows you to say so?" syndrome); and explicative, objective, "cold" sociological analyses on the other side, with a higher requirement of evidence-but keeping too far from what art or music are about to be acknowledged by the "groups concerned" (Dewey 1927).

Understanding the work of art as a mediation, in keeping with the lesson of critical sociology, means reviewing the work in all the details of the gestures, bodies, habits, materials, spaces, languages, and institutions that it inhabits. Without accumulated mediations - styles, grammar, systems of taste, programs, concert halls, schools, 
entrepreneurs, and so on - no beautiful work of art appears. At the same time, however-and against the usual agenda of critical sociology - we must recognize the moment of the work in its specific and irreversible dimension; this means seeing it as a transformation, a productive work, and allowing oneself to take into account the (highly diversified) ways in which actors describe and experience aesthetic pleasure (Hennion 2007; DeNora 2011).

For various reasons, this has for long not been the case within social studies of music. The sterile opposition between theoretical and empirical programs was not clearly superseded. In the case of literature or the visual arts, the sociological approach was prepared by lengthy debate over the merits of internal and external explanations. Even if the terms of this debate proved to be unsatisfactory in the end, the debate has at least occurred; in the case of music, the fight has not taken place. Music has always puzzled the critical discourse of the social sciences: here there is an art obviously collective but technical and difficult to grasp, and with no visible object to contest. As music had a priori no explicit "content," the opposition between internal and external approaches was difficult to mobilize. To what could one refer an opposition between a formalist and a realist interpretation of musical works? The positivistic character of much traditional musicology, with little theoretical self-questioning, has often been criticized, while a purely grammatical analysis of musical language produced its own closed sphere. With little relationship to either, a history of music could then describe all the concrete forms through which music had been created, performed, and listened to. The social status of musicians, the technical and economic development of musical instruments, changes in concerts and musical life: studies of all these elements have accumulated, producing rich insights and results, but without any possibility of relating them to musical works, languages, or "contents" in other than very intuitive or metaphorical terms. Instead of giving birth to fruitful controversies and passionate polemics, music has allowed different disciplines to grow, and to ignore one another.

In the case of the visual arts, the materiality of the works, even and especially if challenged by the artists, has allowed a debate to take place about the social production and reception of art. Music is in the reverse situation: its object is elusive; social interpretations just take it as the expression of a social group (ethnic trance, rock concert), aesthetic studies as a nonverbal language of immediacy. Music has nothing but mediations to show: instruments, musicians, scores, stages, records. The works are not "already there," faced with differences in taste also "already there," overdetermined by the social. They always have to be played again or, to say it better, performed anew (Schechner 2002; Butler 2005).

\section{The Lesson of Music}

But what was a handicap for the older, formerly dominant critical approach can become an asset if the aim is to envisage a positive conception of mediation (Hennion [1993] 2007). Patrons, sponsors, markets, academies: from the first undertakings of the social history of art, mediations have always had a crucial role in social analyses (e.g., Baxandall 1972; Haskell 1976). Their critical dimension has been used against aestheticism to recall that works and tastes are constructed and socially determined. But music enables us to go beyond the description of technical and economic intermediaries as mere transformers of the musical relationship into commodities, and to do a positive analysis of all the human and material intermediaries of the "performance" and "consumption" of art, from gestures and bodies to stages and media. Mediations are neither mere carriers of the work, nor substitutes that dissolve its reality; they are the art itself, as is particularly obvious in the case of music: when the performer places a score on his music stand, he plays that music, to be sure, but music is just as much the very fact of playing; mediations in music have a pragmatic status - they are the art that they reveal, and cannot be distinguished from the appreciation they generate. 
Mediations can therefore serve as a base for a positive analysis of tastes, and not for the deconstruction of these tastes.

Various authors have foregrounded the specificity of music's construction, either on the basis of ethnomethodologist or reflexivist claims to take into consideration the way people themselves construct a reality that they call music (Frith 1981; Bergeron and Bohlman 1992), or to account for the fact that we find in music a very particular way of putting a social reality into a form and a practice, and need to cope with the enigma of this art, which is both very immediate, subjective, and emotive, and also highly symbolic, so powerfully able to mobilize groups and carry social identities. To make a sociological analysis of taste does not mean to acknowledge the existence of some general underlying social mechanisms responsible for the presumably stable and necessary relationship between self-enclosed works and preexisting tastes. Rather, taste, pleasure, and meaning are contingent, conjunctural, and hence transient; and they result from specific yet varying combinations of particular intermediaries, considered not as the neutral channels through which predetermined social relations operate, but as productive entities that have effectivities of their own.

One could expect that musical practices, publics, and amateurs would be privileged objects of study for sociologists of music. This is the case with changes in concert life and the development of new musical tastes (Weber 1975, 1992; Morrow 1989; Johnson 1995). The invention of a tradition and the social production of the past has been traced for several repertories, ranging from Beethoven (DeNora 1995) to country music (Peterson 1997). From a more political point of view, Fulcher (1987) has discussed French "Grand Opera" not as a mere petit-bourgeois form of divertissement, as usual, but as a vehicle for the risky political production of the newly restored monarchy's national-popular legitimacy. And after Benjamin's much-debated essay (1973), modern media and the socioeconomic transformation of music and listening that they entail have been widely discussed; for example, in relation to the production of a new "aurality" through the early music recordings (Maisonneuve 2009), to jazz (Berliner 1994), and to rock and popular culture (Laing 1985; Hennion 1989; Frith and Goodwin 1990). More generally, popular music and rock have been sites for rich critical rethinking within cultural, gender, and ethnic studies (Willis 1978; Hebdige 1979; Whiteley et al. 2004; Bennett, A. 2005): what appears to be a blasphemy for occidental music is inescapable for popular music, which is studied as a mixture of rites, of linguistic and social structures, of technical media and marketing strategies, of instruments and musical objects, and of politics and bodies. Often implicitly, social analysis refers to the power of music to establish and actualize the identity of a group, an ethnicity, and a generation, and points to the ambivalence of its political function: music both helps a social entity to access reality, and prevents it from expressing itself through more political means (Brake 1980; Frith 1981; Yonnet 1985; Middleton 1990; Wicke 1990). And after all, Max Weber ([1921] 1958) had done something similar in his much earlier essay-tentative and speculative but full of deep insights - establishing new relations among musical language, technique, and notation, and the social division of labour among audiences, musicians, and composers.

The theme of mediation as an empirical means for identifying the progressive appearance of a work and its reception is very rich; it is the means (for the sociologist) to reopen the work-taste duality, a duality that represents a closure of the analysis, with works on one side left to aestheticians and musicologists, who attribute the power of music to the music itself, and, facing them, a sociological denunciation, the reduction of music to a rite. In the next three sections I briefly exemplify such a "mediation perspective" from some of my own studies.

\section{"Bach Today"}


Bach was not a "modern composer," author of a "Complete Works," catalogued in the BachWerke-Verzeichnis, before musicology, the record industry, and the modern amateur. One can trace through the nineteenth century the long transformation of what was "music," and how it produced our taste for Bach as a musician, giving him the strange ability of being both the object and the means of our love for music (Fauquet and Hennion 2000). Bach is neither the solitary individual born in 1685 to whom history would ascribe an oeuvre, nor an artificial construct of our modern taste. We listen to him today by way of three hundred years of collective labour, and of the most modern mechanisms, mechanisms that we created to listen to him but also because we were listening to him. Those mechanisms keep on perfecting themselves in the desire for a "return to Bach" (thanks to musicology, organology, computerized recording, the progress made by performers, and the historicization of our appreciation). But in so doing, they invest themselves more and more in this active production of "Bach today," and the more and more modern they become!

How can one analyze Bach's grandeur? To answer such a question, one cannot just study "Bach's reception" musicologically. To speak of reception is already to admit that the oeuvre is constituted. Beauty is also in the eye of the beholder: the formation of a taste cultivated for classical music is not simply an independent development that enables the "reception" of the great composer always to be more worthy of him. But one cannot just sociologically critique the cult of Bach: there was, and continues to be, a simultaneous production of a taste for Bach, of an oeuvre corresponding to this taste and, more generally, of a new mechanism for musical appreciation. The hand is not dealt to two partners (Bach and us) but to three (Bach, us, and "the music"), none of which can be separated from the others: Bach's music continually changes in the process, and reciprocally, all through the nineteenth century, Bach helped a complete redefinition of the love for music to take place.

Bach "becomes music": not only a reference, an ancient Master, the statue of the Commendatore in the shadow of whom the music of the present time is written, but a contemporary composer. But the reverse is also true: classical music "becomes Bach," it is reorganized around his figure (and Beethoven's), resting on their production. Bach is not integrated into an already made musical universe: he produces it, in part, through the invention of a new taste for music. Throughout the century, we witness the formation both of a new way to love music, as a serious, demanding activity - a development that was primarily due to the influence of Beethoven and Bach - and of a new repertoire of masterpieces that respond to this appreciation. Bach's "early adopters" in France (Boëly, Fétis, Chopin, Alkan, Gounod, Franck, Liszt, Saint-Saëns) copied, paraphrased, transcribed-not because they were unfaithful, but because Bach was a means for making music, not a composer of the past. Through the way that each incorporated the insights that they discovered in Bach's work into their own compositions, these composers gradually developed our modern form of musical appreciation. Paradoxically, their interaction with Bach's oeuvre also led to the current stipulation that the past be respected, a stipulation that calls us to reject this nineteenth century that brought Bach to us, so as to return to a more original, more authentic Bach, a Bach who is "better" understood (Hennion and Fauquet 2001).

This account reveals the "musicalization" of our taste for the music: the formation of a specific competence, increasingly well defined and self-sufficient, that makes us appreciate the works according to a regime of connoisseurship - a format that we stop seeing as we come to belong to it most naturally and intimately. This is at the heart of the paradoxes surrounding the baroque revival (Hennion 1997): the appearance of a past to listen to in a particular fashion, by respecting its modes of production, is the incredibly elaborated-and very modern - fruit of a hypertrophy of musical taste, based on musicology and the progress in recording. It is the culmination of a transformation of musical taste, not a passive and anachronistic "return to sources." Nothing is more modern than an historical approach to an 
old repertoire.

\section{Jazz, Rock, Rap, and Their Media}

Comparing musics and genres on the basis of the media and modes of performance they use does not mean taking their self-descriptions at face value. It is too easy, for instance, to oppose the freedom of playing together and the pleasure of dancing bodies, identified in jazz or rock, to the way written music gives itself airs, while it is suspected by its opponents to be already dead. Against the supposed rigidity of a corseted classical music-prisoner of scores, orchestral hierarchies, harmonic "laws" - jazz, which is so fond of old records, assumes its sweetest voice to sing praises of improvisation. But, busy adorning the object of her love with these praises, the jazz lover forgets that this splendid transgression of centuries of written music did not come about by going back to the oral sources of a traditional music that cannot be written down on paper, but on the contrary by going forward with the use of new means to overfix music, through a medium that no former genre could lean on: jazz has been written by recordings. Testimonies from all the jazz greats converge: they have trained, they have practiced scales, with one ear stuck at the gramophone and radio. Parker learns how to "chorus" by listening hundreds of times to Hawkins's or Young's solos on an old record player, just as previous generations wore out their eyes on old scores, and he looks for the same thing they did: to read a music he could not hear at its source, but that these recordings allow him to work and rework, to analyze and copy, and to play, note by note, faster and faster (DeVeaux 1997).

As a result, far from obeying the millennial rhythm of traditional musics that (transmitted only through collective repetition) continuously change without changing, never stop moving while thinking themselves eternally the same, jazz covered in fifty years a history classical music took five hundred years to write. Between an old blues and a chorus by Coltrane, both officially improvised, lies a transition from orality to a music that on the contrary is overwritten, even more written than classical pieces. Records have written jazz's library. Its living history is the fruit of mechanical recording.

Another example: the sudden passage from rock to rap, quite similar to the revolution of rock itself in the fifties, also displays a conflict between different media-stage versus record. Through a face-to-face confrontation between the star and the public, rock constructed its power around a mythic stage in the quest for a lost hand-to-hand clinch between idols and people. This central place given to the stage was destroyed by rap from the very start, giving way to another definition of musical truth: where you live, where you hang out. The denunciation of rock's too-sophisticated techniques, already made by punks, and the bricolage with record decks and boom boxes, exposed rock's "archaic" conception of stage performance on the basis of an unexpected promotion of recording: not as a faithful reproduction medium, but a cheap means for local creation.

By explicitly refusing to refer to a place other than where one lives - the street, the pavement, shared and invaded places, where one talks, fights, discusses - rap at its origin interrupted the very gesture of the great stage performance. It commuted rivalries and fights into an improvisatory sparring match based on a given background music, played on equipment whose quality did not matter as long as the music was loud enough, to be listened to on the spot, by buddies, equals. The truth of music is not in music itself, not in any reconstituted collective, it is in the present performance you can give, here and now. The initial hostility of rappers toward the music business, money, and the mass media is less to be interpreted as political radicalism than as the technical means to stop the move of identities toward the big stage, always in the hands of intermediaries - and of the white man. So defined, rap is not so new: bebop in its time, punk more recently, or neobaroque musicians all 
began by escaping from the big stage and the media, before being seized back or dying. Rap has already suffered this common fate. But before it became just another musical genre and social style - racking up huge sales for the record industry - rap had produced, besides a blow to rock grandeur, a new and lasting instrumental use of "reproduction" technology.

\section{Figures of Amateurs}

When a sociologist questions somebody nowadays on what he likes, his subject apologizes. "My family is very bourgeois, my sister plays the violin...." Far from revealing the hidden social reality of tastes thought of by amateurs as personal and subjective, irreducible and absolute, sociology has become one of the main registers in which to speak about them. Music lovers, fully aware that tastes are relative, historical, and the supports of various social rites, display them as arbitrary, socially determined signs. Strange paradox of a highly reflexive field: it is the sociologist who must henceforth "desociologize" the amateur if he wants her to speak back of her pleasure, of what holds her, of the astonishing techniques and tricks she develops in order to reach, sometimes, her joy.

Far from being the cultural dope at whose expense the sociology of culture built its critical fortune, the amateur (in the broad sense of art lover) is a virtuoso of experimentation, be it aesthetic, technical, social, mental, or corporeal. She is the model of an inventive and reflexive actor, tightly bound to a collective, continuously forced to put into question the determinants of what she likes. She is as self-aware about pieces and products as about the social determinants and mimetic biases of her preferences; about the training of her body and soul as about her ability to like music, the technical devices of appreciation and the necessary conditions of a good feeling, the support of a collective and the vocabulary progressively designed to perform and intensify her pleasure. Studying diverse amateurs, then, provides a better understanding of our attachments (Gomart and Hennion 1999; Hennion 2001).

Such a survey of classical music lovers, through all the means they can use to reach music (instruments, choirs, singing, but also records, concerts, media, and the Internet), displays the various and heteronomous moments, formats, and configurations in the careers of amateurs, their pattern depending less on past determinants than revealing the stages of a problematic relation to an evasive object (Hennion 2007). A systematic comparison between wine amateurs and music lovers puts under scrutiny the variable role of the heterogeneous mediations of taste: techniques of buying and tasting; belonging to clubs or organized groups; use of an idiomatic vocabulary somewhere between technical discourse and emotive selfexpression; the role of critiques and guides; modes of evaluation, status games, and so forth. Bodies, spaces, durations, gestures, regular practice, technical devices, objects, guides, apprenticeship: both music as a performing art and wine because of its focus on a corporeal contact with the eye, the nose, and the palate allow us to understand taste not as a recording of fixed properties of an object, not as a stable attribute of a person, and not as a game played between existing identities, but as an accomplishment. It is not about liking music or being a wine taster, but about being touched by this piece or liking this bottle, here, now, with these people: a strange activity, the conditions of which are continuously discussed by amateurs themselves. It relies closely upon moments, places, opportunities: taste is not only an activity, it is an event, oversensitive to the problematic relationship between - as they nicely say - a combination of circumstances.

\section{A Possible Return to the Work?}

A last point, about the work "itself" - this silent other side of the coin for the sociology of art. A rewriting of music from the viewpoint of mediation makes artistic creation somewhat less 
distant, less difficult to think of for sociology. Creation does not need to be "taken away" from the great composers and given back to society or consumers: it is just more distributed. Creation is not only on the side of the creator; on the contrary, the more there is a collective work in defining and thus creating a domain such as music, the more we will end up attributing the origins of the works exclusively to certain creators - the paradox of the "author," which the theoreticians of literature have clearly pointed out (Foucault 1969). This mechanism is profoundly circular: it takes all the collectivity's love to be able to say that everything comes from Rembrandt or Mozart. This is why Elias (1993) is caught in a double bind when he speaks of Mozart as a "socially unrecognized" genius - a paradoxical pleonasm, considering how much this "unrecognition" is a central figure of the social recognition of "genius." Highlighting the work of mediation consists of descending a little from this slightly crazy position of attributing everything to a single creator, and realizing that creation is far more widely distributed, that it takes place in all the interstices between these successive mediations. It is not despite the fact that there is a creator, but so that there can be a creator, that all our collective creative work is required.

This collective redistribution of creation is a counterpoint to the single attribution - the "all to the author" - in the preceding period. There is an optimistic note here: This redistributed creation, always out of line, has no need to be compared to the original work as if to a sort of paralyzing challenge. Creation only uses the elements that it holds to make-with a slight discrepancy-something else: a new creation. It is less a question of understanding everything (a formula whose epistemological terrorism is readily apparent) than of grasping something at work, from which a constantly changing interpretation can be presented.

\section{References}

Bennett, Andy. 2000. Popular Music and Youth Culture: Music, Identity and Place. Basingstoke: Macmillan.

Bennett, Andy. 2005. Culture and Everyday Life. London: Sage.

Berliner, Paul F. 1994. Thinking in Jazz. The Infinite Art of Improvisation. Chicago: The University of Chicago Press.

Butler, Judith. 2005. Giving An Account of Oneself. New York: Fordham University Press. DeNora, Tia. 2000. Music in Everyday Life. Cambridge: Cambridge University Press.

DeNora, Tia. 2011. Music-in-Action: essays in sonic ecology. Aldershot: Ashgate.

DeVeaux, Scott. 1997. The Birth of BeBop. A Social and Musical History. Berkeley: The University of California Press.

Dewey, John. 1927. The Public and its Problems. NY: Holt.

Frow, J. 1995. Cultural Studies and Cultural Value. Oxford: Clarendon Press.

Gell, Alfred. 1998. Art and Agency. An Anthropological Theory. Oxford: Oxford University Press.

Grossberg, Larry, et al., eds. 1992. Cultural Studies. London: Routledge.

Hall, Stuart, and T. Jefferson, eds. 1976. Resistance Through Rituals. Youth Subcultures in Post-War Britain. London: Routledge.

Hennion, Antoine. 2004. Pragmatics of taste. In Jacobs, Mark, and Nancy Hanrahan, eds. The Blackwell Companion to the Sociology of Culture. Oxford UK/Malden MA: Blackwell: 131-144. Hennion, Antoine. [1993] 2007. La Passion musicale. Paris: Métailié.

Hennion, Antoine. 2007. Those Things That Hold Us Together. Cultural Sociology 1-1: 97-114.

Maisonneuve, Sophie. 2009. L'invention du disque, 1877-1949. Paris: EAC.

Peterson, Richard A., and Roger M. Kern. 1996. "Changing Highbrow Taste: from Snob to

Omnivore.” American Sociological Review 61: 900-07.

Schechner, Richard. 2002. Performance Studies. Oxon: Routledge.

Whiteley, Sheila, Andy Bennett, and Stan Hawkins, eds. 2004. Music, Space and Place: Popular Music and Cultural Identity. Aldershot: Ashgate. 


\section{Further Reading}

Bennett, H. Stith. 1980. On becoming a rock musician. Amherst, MA: University of Massachusetts Press.

Bennett, Tony, Simon Frith, Larry Grossberg, John Shepherd, and Graeme Turner, eds. 1993. Rock and popular music: Politics, policies, institutions. London: Routledge.

Bennett, Tony, M. Emmison, J. Frow. 1999. Accounting for Tastes. Australian Everyday Cultures.

Cambridge: Cambridge University Press.

Chaney, David. 2002. Cultural Change and Everyday Life. Basingstoke: Palgrave.

Cutler, Chris. 1985. File under popular. Theoretical and critical writings on music. London: November Books.

Durant, Alan. 1984. Conditions of music. London: Macmillan.

Frith, Simon. 1978. The Sociology of Rock. London: Constable.

Gumplowicz, Philippe. [1987] 2001. Les travaux d'Orphée. Deux siècles de pratique musicale amateur en France; harmonies, chorales, fanfares. Paris: Aubier.

Hennion, Antoine, Sophie Maisonneuve, and Émilie Gomart. 2000. Figures de l'amateur. Forme, objets et pratiques de l'amour de la musique aujourd'hui. Paris: La Documentation française.

Jacobs, J.M. 1996. Edge of Empire. Postcolonialism and the City. London, New York: Routledge.

Laborde, Denis. 1997. De Jean-Sébastien Bach à Glenn Gould. Magie des sons et spectacle de la passion. Paris: L'Harmattan.

Leppert, Richard, and Susan McClary, eds. 1987. Music and society: The politics of composition, performance and reception. Cambridge, U.K.: Cambridge Univ. Press.

Savage, Mike, G. Bagnall, and B.J. Longhurst. 2005. Globalisation and Belonging. London: Sage.

Scott, Derek. 2000. Music, Culture, and Society. Oxford: Oxford University Press.

Weinstein, D. 2000. Heavy Metal: The Music and its Culture. New York: Da Capo Press.

White, Avron Levine, ed. 1987. Lost in music: Culture, style and the musical event. London: Routledge and Kegan Paul. 